\title{
Computer-Assisted Total Knee Arthroplasty: Comparisons with the Conventional Technique
}

\author{
TOSHIRO SHINOZAKI, MASAFUMI GOTOH*, YASUHIRO MITSUI, YOSHIMASA HIRAI, \\ TAKAHIRO OKAWA*, FUJIO HIGUCHI* AND KENSEI NAGATA
}

\author{
Department of Orthopaedic Surgery, Kurume University School of Medicine, Kurume 830-0013, \\ *Department of Orthopaedic Surgery, Kurume University Medical Center, Kurume 839-0863, Japan
}

Received 3 June 2010, accepted 24 February 2011

\author{
Edited by TAKAAKI FUKUDA
}

\begin{abstract}
Summary: For successful total knee arthroplasty (TKA), it is very important to gain an accurate grasp of the mechanical axis of the lower limb and establish a suitable ligament balance. Recently, TKA using navigation systems has been developed to accomplish more accurate component placement and to achieve a better understanding of the mechanical axis. The purpose of this study was to compare the radiological results of computer-navigated TKA with those of conventional TKA. We prospectively evaluated 75 primary TKAs (75 subjects) that were performed using a cruciate-retaining prosthesis of the same model at our institution. The subjects were allocated alternately to a navigation group ( 37 knees) and a conventional group (38 knees). Postoperative radiographs were taken in the standing position at 12 weeks after surgery, and were evaluated in accordance with the report of Bäthis et al. [1]. No significant difference in preoperative profiles was observed between the two groups. At the postoperative radiographic evaluation, significantly better results were obtained in the navigation group with regard to the mechanical axis and the component, but the results were less conclusive in the lateral femoral component position. Our findings suggest that computer-navigated TKA is useful for obtaining more accurate results. However, the present study was limited by the small number of subjects and short follow-up period, and therefore further study involving more subjects and a longer-term follow-up will be needed.
\end{abstract}

Key words computer-assisted total knee arthroplasty, cruciate-retaining prosthesis, radiographic evaluation, mechanical axis, alignment of the component

\section{INTRODUCTION}

Total knee arthroplasty (TKA) has been established as a surgical method for treatment of osteoarthritis of the knee. Previous studies with long-term follow-up have demonstrated that $80 \%$ of patients who undergo TKA are satisfied with the results [2,3]. Such studies consistently showed that the mechanical axis and ligament balance are important factors to consider for obtaining good clinical results.

The postoperative mechanical axis in TKA is usually within $\pm 3^{\circ}$ of the planned axis, and deviation from this can lead to early loosening [4-7]. A postoperative mechanical axis within $\pm 3^{\circ}$ after TKA was noted in $74 \%$ of patients ( 37 of 50 ) in a study by Petersen and Engh [8], and $75 \%$ (469 of 637) in a study by Mahaluxmivara et al. [9].

Varus/valgus placement of the femoral and tibial components can similarly lead to loosening [10]. A change in the joint line affects the range of motion [11], as does retroversion of the tibial component $[12,13]$.

Navigation systems have been developed to obtain a more accurate grasp of the mechanical axis and aid in placement of the components in TKA. Mielke et al.

Correspondence: Masafumi Gotoh, MD, Department of Orthopaedic Surgery, Kurume University Medical Center, Kurume 839-0863, Japan. Tel: +81-94222-6111 Fax: +81-942-22-6657 E-mail:gomasa@med.kurume-u.ac.jp

Abbreviations: TKA, total knee arthroplasty; HKA angle, hip-knee-ankle angle; FFC angle, frontal femoral component angle; FTC angle, frontal tibial component angle; LFC angle, lateral femoral component angle; LTC angle, lateral tibial component angle; FTA, femorotibial angle. 
[14] compared the use of a navigation system with the conventional method and reported that the former achieved better postoperative alignment. Conversely, Jenny and Boeri [15] stated that there was no significant difference between the use of a navigation system and the conventional approach. In the present study, we performed a radiographic evaluation of a CT-free navigation system, and compared it with the conventional method.

\section{MATERIALS AND METHODS}

\section{Subjects}

Primary TKA was performed on 281 patients at the Kurume University Medical Center between April 2003 and December 2005. Of these patients, 75 were chosen as the study subjects, and 37 were allocated to a navigation group and 38 to a conventional group. The same type of implant (TC Plus, EndoPlus, Switzerland) was used for all patients in both groups. Before surgery, the purpose of the present study was explained to the patients, and their informed consent was obtained.

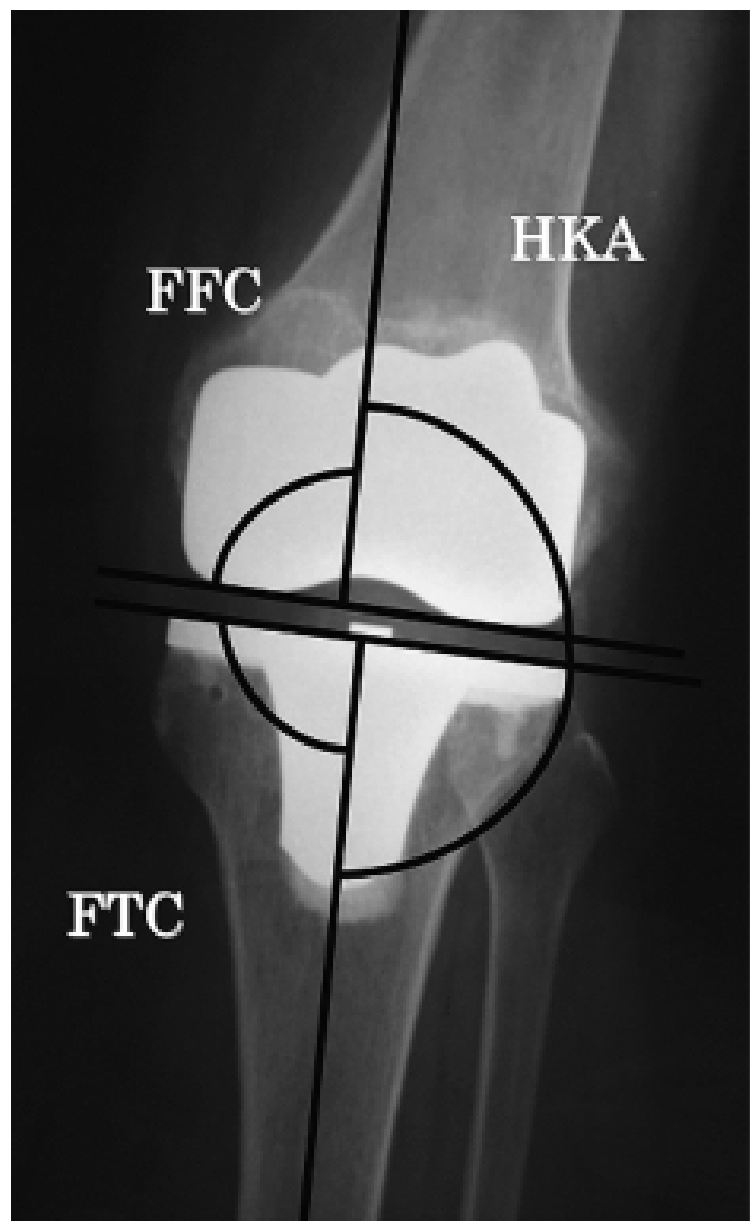

Fig. 1A.

\section{Surgical technique}

The surgical procedure was performed in accordance with the manufacturer's instructions. Specifically, femoral osteotomy was performed using an intramedullary rod through medial parapatellar approach, and an external rotation of $3^{\circ}$ was the index for femoral rotation with reference to the posterior condylar line. Tibial osteotomy was performed using an extramedullary rod, and the posterior inclination was set at $5^{\circ}$.

\section{Computer-assisted technique}

A CT-free navigation system (Garireo, Endplus, Switzerland) was used in the navigation group. This is a system for detecting waves that are reflected from a marker on a spherical object using an infrared camera. The marker was firmly fixed to the distal femur, the femur was moved in an arbitrary direction around the hip joint, and 16 points were obtained. In addition, 24 reference points were input using a stylus with a marker. The resulting measurements were analyzed, and a model of the femur was generated by a computer, followed by adjustment of the alignment, and the rotation as well as the varus-valgus line was checked visually using an alignment guide. Based on this approach, the sites for osteotomy were established so that the cut block attached to the femur was aligned with the mechanical axis from the front view and had a flexion angle of $5^{\circ}$ on the front face of the femoral component

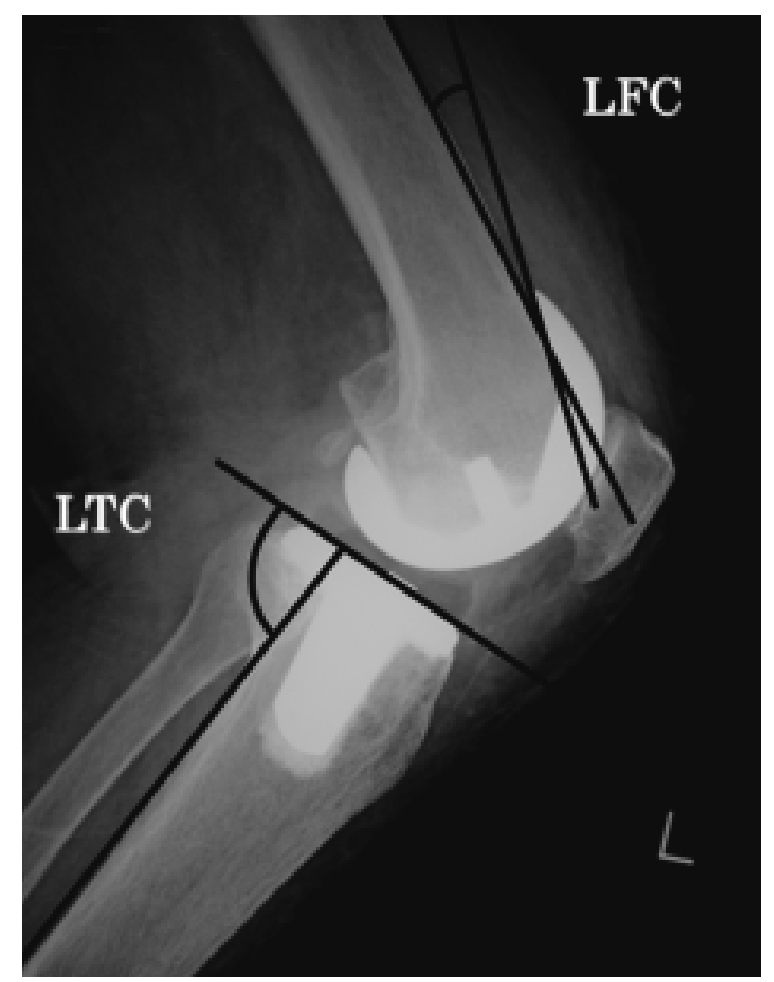

Fig. $1 B$. 
from the lateral view, and each osteotomy was performed under visual observation.

On the tibial side, a tibial base plate was placed at the distal tibia and a marker was fixed to it. Six arbitrary reference points were input, and a model of the tibial bone was reproduced on the computer, in the same way as for the femur. On this basis, the posterior inclination of the tibia was set at $5^{\circ}$, and the bone was cut perpendicularly to the tibial axis.

After the osteotomy, a trial placement was conducted, and the range of motion and the varus-valgus alignment were verified on the image via flexion and extension of the knee joint.

\section{Radiological measurement}

For postoperative radiographic evaluation, X-ray films were obtained in the frontal and sagittal views at 12 weeks after the surgery with the patient in a standing position. Measurements were performed in accordance with the method of Bäthis, et al. [1]. For the mechanical axis and frontal alignment, the hipknee-ankle (HKA) angle (= mechanical axis of the limb), the frontal femoral component (FFC) angle, and the frontal tibial component (FTC) angle were measured (Fig. 1A). For the sagittal view, the lateral femoral component (LFC) angle and the lateral tibial component (LTC) angle were evaluated (Fig. 1B).

These measurements were performed by an experienced orthopedist who was not involved in the present study.

\section{Statistical analysis}

The ideal range of each angle and "outliers" were defined based on a range of $\pm 3^{\circ}$ varus/valgus and $\pm 3^{\circ}$ flexion/extension [16]. For statistical evaluation, the $t$ test, the Fisher test, and the Mann-Whitney test were used. A P value of $<0.05$ was considered to indicate a significant difference.

\section{RESULTS}

Preoperative profiles in the navigated and conventional groups

It was possible to evaluate all of the 75 patients enrolled. There were 5 males and 32 females in the navigation group, with an average age of 74.7 (range: 62 years to 86) years, including 31 with osteoarthritis (OA) and 6 with rheumatoid arthritis (RA). The average preoperative femorotibial angle (FTA) was $185.7^{\circ}$ (range: $140^{\circ}$ to $200^{\circ}$ ). In the conventional group, there were 8 males and 30 females, with an average age of 74.0 (range: 46 years to 89 ) years, including 32 with $\mathrm{OA}$ and 6 with RA. The average FTA was $185.3^{\circ}$ (range: $170^{\circ}$ to $204^{\circ}$ ). There was no significant difference in these preoperative factors between the two groups (t-test). Details are summarized in Table 1.

\section{Mechanical axis of the leg}

The average postoperative mechanical axis (HKA) was $180.6 \pm 2.8^{\circ}$ in the navigation group and 181.2 \pm $4.1^{\circ}$ in the conventional group, the mechanical axis of the navigation group being significantly closer to $180^{\circ}$ $(\mathrm{P}=0.0232$, F-test). Outlier values of the mechanical axis were seen for 6 patients $(16.3 \%)$ in the navigation group and 16 patients $(42.1 \%)$ in the conventional group. Details are shown in Table 2.

\section{Alignment of the component}

The average FFC angle was $90.1 \pm 1.8^{\circ}$ in the navigation group and $89.4 \pm 2.7^{\circ}$ in the conventional group, being significantly closer to $90^{\circ}$ in the former $(\mathrm{P}=0.0198$, F-test). Outlier values of the FFC angle were seen in 1 patient $(2.8 \%)$ in the navigation group and 5 patients $(13.2 \%)$ in the conventional group. The outliers in both groups were within $90^{\circ} \pm 5^{\circ}$. The FTC angle was $90.2 \pm 1.5^{\circ}$ in the navigation group and $89.7 \pm 2.2^{\circ}$ in the conventional group, being significantly closer to $90^{\circ}$ in the former $(\mathrm{P}=0.014, \mathrm{~F}$-test $)$. Outlier values of

TABLE 1.

Preoparative profiles

\begin{tabular}{lccc}
\hline & Navigation system & Conventional technique & P-value \\
\hline Age & $74.8(5.4)$ & $74.0(7.5)$ & 0.6288 \\
Male & 5 & 8 & $\square$ \\
Female & 32 & 30 & -5437 \\
OA & 31 & 32 & $\square$ \\
RA & 6 & 6 & \\
FTA & $185.7^{\circ}(12)$ & $185.3^{\circ}(7.8)$ & 0.000 \\
\hline
\end{tabular}


TABLE 2.

Coronal axis alignment

\begin{tabular}{|c|c|c|c|c|c|}
\hline & \multicolumn{2}{|c|}{ Navigation system } & \multicolumn{2}{|c|}{ Conventional technique } & \multirow{2}{*}{ P-value } \\
\hline & $\mathrm{n}$ & & $\mathrm{n}$ & & \\
\hline $\begin{array}{l}\text { HKA } \\
\quad \text { outlier }\end{array}$ & 37 & $\begin{array}{c}180.6^{\circ}(2.8) \\
16.3 \%\end{array}$ & 38 & $\begin{array}{c}181.2^{\circ}(4.1) \\
42.1 \%\end{array}$ & 0.0232 \\
\hline $\begin{array}{l}\text { FFC } \\
\quad \text { outlier }\end{array}$ & 37 & $\begin{array}{c}90.1^{\circ}(1.8) \\
2.8 \%\end{array}$ & 38 & $\begin{array}{c}89.4^{\circ}(2.7) \\
13.2 \%\end{array}$ & 0.0198 \\
\hline $\begin{array}{l}\text { FTC } \\
\quad \text { outlier }\end{array}$ & 37 & $\begin{array}{c}90.2^{\circ}(1.5) \\
0.0 \%\end{array}$ & 38 & $\begin{array}{c}89.7^{\circ}(2.2) \\
15.6 \%\end{array}$ & 0.014 \\
\hline
\end{tabular}

TABLE 3

Sagital alignment

\begin{tabular}{|c|c|c|c|c|c|}
\hline & \multicolumn{2}{|c|}{ Navigation system } & \multicolumn{2}{|c|}{ Conventional technique } & \multirow{2}{*}{$\mathrm{P}$-value } \\
\hline & $\mathrm{n}$ & & $\mathrm{n}$ & & \\
\hline $\begin{array}{l}\text { LFC } \\
\quad \text { outlier }\end{array}$ & 37 & $\begin{array}{c}8.5^{\circ}(3.5) \\
45.9 \%\end{array}$ & 38 & $\begin{array}{c}8.5^{\circ}(3.1) \\
42.1 \%\end{array}$ & 0.4955 \\
\hline $\begin{array}{l}\text { LTC } \\
\quad \text { outlier }\end{array}$ & 37 & $\begin{array}{c}3.8^{\circ}(1.9) \\
7.9 \%\end{array}$ & 38 & $\begin{array}{c}3.5^{\circ}(2.8) \\
27.0 \%\end{array}$ & 0.0118 \\
\hline
\end{tabular}

the FTC angle were seen in $0(0 \%)$ of the navigation group and 6 patients $(15.6 \%)$ in the conventional group. The outliers in the conventional group were within $90^{\circ} \pm 5^{\circ}$. Details are shown in Table 2 .

The average LFC angle was $8.5 \pm 3.5^{\circ}$ in the navigation group and $8.5 \pm 3.1^{\circ}$ in the manual group, being non-significantly closer to $5^{\circ}$ in the navigation group $(\mathrm{P}=0.4955$, F-test). There were 17 (45.9\%) LFC angle outliers in the navigation group and $16(42.1 \%)$ in the

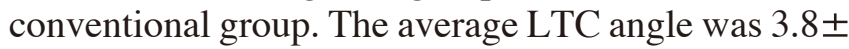
$1.9^{\circ}$ in the navigation group and $3.5 \pm 2.8^{\circ}$ in the conventional group, being significantly closer to $5^{\circ}$ in the former ( $\mathrm{P}=0.0118$, F-test). There were 3 (7.9\%) LTC angle outliers in the navigation group and $10(27 \%)$ in the conventional group. Details are shown in Table 3.

In the present series, there was no instance in which the procedure was changed from navigation to conventional during surgery, and no significant complications were encountered. The operation time was $106 \pm 21 \mathrm{~min}$ for the navigation group and $95 \pm 10 \mathrm{~min}$ for the conventional group ( $\mathrm{p}=0.0163$, Mann-Whitney test). The average length of the skin incision was 24.8 $\mathrm{cm}$ in the navigation group and $19.5 \mathrm{~cm}$ in the conventional group $(\mathrm{p}<0.0001$, Mann-Whitney test).

\section{DISCUSSION}

Proper mechanical limb alignment in TKA is an important factor for obtaining good postoperative results. Malposition of the TKA implant results in early loosening and accelerated polyethylene wear $[4,7,16]$. Valgus/varus malalignment can result in early postoperative complications, including loosening, instability, and polyethylene wear may occur [4-7].

To obtain a proper mechanical axis in TKA, the use of a navigation system has been developed and analyzed in previous studies comparing the radiological accuracy of the component placement between navigated and conventional TKA. However, plain radiographs have been commonly used for radiological evaluation [16], despite the limitations imposed by imaging errors [16,17-19], possibly leading to a statistical bias in analysis of the radiological results. In the present study, the consistency of alignment for each radiological parameter was assessed by setting outliers based on $\pm 3^{\circ}$ varus/valgus or $\pm 3^{\circ}$ flexion/extension, in accordance with the approach of Jung et al. [16].

For TKA using a navigation system, the mechanical axis was reported to be within $\pm 3^{\circ}$ in $96 \%$ of subjects (77 of 80 ) in a study by Bäthis et al. [1], 92\% (217 of 235) in a study by Jenny et al. [20], 71\% (26 of 32 ) in a study by Inoue et al. [19], and 87\% (13 of 15) in a study by Taki et al. [21]. In the present investigation, the axis was within $3^{\circ}$ in $84 \%$ of subjects ( 31 of 37) who underwent TKA with the navigation system, and was within $5^{\circ}$ in the remaining $16 \%$ (6 of 37). Our results also demonstrated that the proportion of patients in whom the postoperative mechanical axis was within 
$3^{\circ}$ was significantly greater in the navigation group than in the conventional TKA group.

Conventional TKA aims to achieve a mechanical axis within $180 \pm 3^{\circ}$ [4-9]. Petersen and Engh [8] reported that the mechanical axis was within $180 \pm 3^{\circ}$ in $74 \%$ ( 37 of 50) of patients who underwent conventional TKA, compared with $72 \%$ (170 of 235) in the study by Jenny et al. [20], 69\% (22 of 32) in the study by Inoue et al. [19], and 47\% (7 of 15) in the study by Taki et al. [21]. In the present study, the mechanical axis was within $180 \pm 3^{\circ}$ in $58 \%$ of subjects ( 22 of 38 ) after conventional TKA, and within $180 \pm 5^{\circ}$ in the remaining $42 \%$ ( 16 of 38 ).

Previous reports have demonstrated variability of the LFC angles in conventional TKA $[1,17,18]$. With the conventional technique, the LFC position is not always optimal, because it depends on the diameter of the intramedullary rod, the insertion point, and the length of the rod. By contrast, the LFC can be placed more accurately by navigated TKA, with reference to the center of the femoral head and the direction of the femoral axis [20]. The present study, however, demonstrated no significant difference in LFC between the two groups. This may indicate a degree of measurement error due to anterior bowing of the femur in navigation TKA [22], or pointing error for the center of the femoral head [1]. As with the CT-based navigation system, these errors may be reduced by creating an accurate 3D model [24].

The present study demonstrated that the LTC angle was more accurate in navigated TKA than in conventional TKA, in agreement with previous reports $[1,17,18]$. In the conventional method, the LTC angle may vary because of differences of the tibial posterior slope in each patient [1], cutting error due to deflection of the bone saw [23], and/or stylus pointing error [25].

Limitations of the present study included the small number of subjects analyzed and the short follow-up period. However, we were able to demonstrate the characteristics of navigated TKA for component placement in comparison with conventional TKA. Future studies involving a larger number of subjects and a longer period of follow-up will be needed. Furthermore, comparison with a CT-based navigation system may also be necessary.

In the present study, we compared the mechanical axis of the lower limb and the position of the component placement in TKA using a CT-free navigation system with those of conventional TKA. The results indicated that the mechanical axis and component placement were more accurate with navigated TKA, except for the LFC angle. The potential benefits of nav- igated TKA in terms of long-term outcome and functional improvement await further clarification.

\section{REFERENCES}

1. Bäthis H, Perlick L, Tingart M, Lüring C, Zurakowski D et al. Alignment in total knee arthroplasty. A comparison of computer-assisted surgery with the conventional technique. J Bone Joint Surg Br 2004; 86:682-687.

2. Robertsson O, Dumbar M, Pehrsson T, Knutson K, and Lidgren L. Patient satisfaction after knee arthroplasty: a report on 27,372 knees operated on between 1981 and 1995 in Sweden. Acta Orthop Scand 2000; 3:262-267.

3. Robertsson O, Knutson K, Lewold S, and Lidgren L. The Swedish Knee Arthroplasty Register 1975-1997: an update with special emphasis on 41,223 knees operated on in 1988-1997. Acta Orthop Scand 2001; 72:503-513.

4. Jeffery RS, Morris RW, and Denham RA. Coronal alignment after total knee replacement. J Bone Joint Surg Br 1991; 73:709-714.

5. Bargren JH, Blaha JD, and Freeman MA. Alignment in total knee arthroplasty. Correlated biomechanical and clinical observations. Clin Orthop Relat Res 1983; 173:178-183.

6. Lotke PA, and Ecker ML. Influence of positioning of prosthesis in total knee replacement. J Bone Joint Surg Am 1977; 591:77-79.

7. Rand JA, and Coventry MB. Ten-year evaluation of geometric total knee arthroplasty. Clin Orthop Relat Res 1988; 232:168-173

8. Petersen TL, and Engh GA. Radiographic assessment of knee alignment after total knee arthroplasty. J Arthroplasty 1988; 3:67-72.

9. Mahaluxmivala J, Bankes MJ, Nicolai P, Aldam $\mathrm{CH}$, and Allen PW. The effect of surgeon experience on component positioning in 673 Press Fit Condylar posterior cruciatesacrificing total knee arthroplasties. J Arthroplasty 2001; 16:635-640.

10. Oswald MH, Jakob RP, Schneider E, and Hoogewoud HM. Radiological analysis of normal axial alignment of femur and tibia in view of total knee arthroplasty. J Arthroplasty 1993; 8:419-426.

11. Rhoads DD, Noble PC, Reuben JD, Mahoney OM, and Tullos HS. The effect of femoral component position on patellar tracking after total knee arthroplasty. Clin Orthop Relat Res 1990; 260:43-51.

12. Dorr LD, and Boiardo RA. Technical considerations in total knee arthroplasty. Clin Orthop Relat Res 198; 205:511.

13. Piazza SJ, Delp SL, Stulberg SD, and Stern SH. Posterior tilting of the tibial component decreases femoral rollback in posterior-substituting knee replacement: a computer simulation study. J Orthop Res 1998; 162:264-270.

14. Mielke RK, Clemens U, Jens JH, and Kershally S. Navigation in knee endoprosthesis implantation - preliminary experiences and prospective comparative study with conventional implantation technique. Z Orthop Ihre Grenzgeb 2001; 139:109-116.

15. Jenny JY, and Boeri C. Navigated implantation of total 
knee endoprostheses - a comparative study with conventional instrumentation. Z Orthop Ihre Grenzgeb 2001; 139(2):117-119.

16. Jung YB, Lee HJ, Jung HJ, Song KS, Lee JS et al. Comparison of the radiological results between fluoroscopy-assisted and navigation-guided total knee arthroplasty. Knee Surg Sports Traumatol Arthrosc 2009; 17:286-292.

17. Chauhan SK, Scott RG, Breidahl W, and Beaver RJ. Computer-assisted knee arthroplasty versus a conventional jig-based technique. A randomised, prospective trial. J Bone Joint Surg Br 2004; 86:372-377.

18. Matsumoto $\mathrm{T}$, Tsumura $\mathrm{N}$, Kurosaka M, Muratsu $\mathrm{H}$, Kuroda $\mathrm{R}$ et al. Prosthetic alignment and sizing in computer-assisted total knee arthroplasty. Int Orthop 2004; 28:282-285.

19. Inoue R, Ishibashi $Y$, Tsuda E, Yamamoto $Y$, and Tsukada H. Alignment of lower extremity after navigation-assisted total knee arthroplasty. -A comparison with the conventional technique- : East-Japanese Society of Orthopedics and Traumatology 2008; 20:528-532.

20. Jenny JY, Clemens U, Kohler S, Kiefer H, Konermann W et al. Consistency of implantation of a total knee arthro- plasty with a non-image-based navigation system: a case-control study of 235 cases compared with 235 conventionally implanted prostheses. J Arthroplasty 2005; 20:832-839.

21. Taki K, Majima T, Onodera S, Yamazaki S, Oura H et al. Alignment of lower limb after navigation-assisted total knee arthroplasty with ligament balancer. Japanese Journal of Replacement Arthroplasty 2005; 35:105-106

22. Takushi N, and Suguro T. Accuracy of computer navigation system for total knee arthroplasty. Bone Joint and Ligament 2003; 16:1453-1460.

23. Plaskos C, Hodgson AJ, Inkpen K, and McGraw RW. Bone cutting errors in total knee arthroplasty. J Arthroplasty 2002; 17:698-705.

24. Martin A, and von Strempel A. Two-year outcomes of computed tomography-based and computed tomography free navigation for total knee arthroplasties. Clin Orthop Relat Res 2006; 449:275-282.

25. Kumahashi N, Naito K, Tobita M, Kohno M, Inoue T et al. The investigation of clinical efficacy of navigation system in alignment of the leg after total knee arthroplasty. Kyushuseikaishi 2006; 18:289-293. 